\title{
A new experience in treatment of congenital hyperinsulinism with long acting octreotide: a case report
}

\begin{abstract}
Congenital hyperinsulinism is a condition, in which the beta cells of pancreas secrete an in appropriately excessive amount of insulin in relation to the existing blood glucose level. The treatment of diffuse form of $\mathrm{HI}$ is difficult and involves intensive medical therapy. Usually after a diagnosis of $\mathrm{CHI}$ is made, a trial of treatment with diazoxide is given for a short period. ${ }^{1}$ However as most of the cases of severe CHIs are caused by genetic mutations of KATP channels, they are unresponsive to diazoxide. ${ }^{2} \mathrm{~A}$ somatostatin analogue, octreotide has been successfully used for around $20 \mathrm{yrs}$ in cases of diazoxide-unresponsive CHI. ${ }^{3}$ This requires 3-4 daily subcutaneous injections or the use of an insulin pump. Long acting somatostatin analogues, LAR octreotide and Lantreotide acetate have been recently used allowing once monthly injections instead of 84 S.C injections over 28 days. ${ }^{2}$ We describe our experience with LAR octreoctide in a Kuwaiti child.
\end{abstract}

Keywords: congenital hyperinsulinism, long acting octreotide, pancreas, diabetes mellitus, hypoglycemia, gallbladder, blood glucose level, diazoxide, octreotide
Volume 3 Issue 4 - 2016

\section{Ayed Al Anezi, Suja Mathew, Ahmed Ibrahim}

Department of Pediatric Endocrinology, Aljahra Hospital, Kuwait

Correspondence: Ayed Al Anezi, Department of Pediatric Endocrinology, Aljahra Hospital, Ministry of Health, Kuwait, Email dr-ayed@hotmail.com

Received: September 0I, 2016 | Published: November II, 2016

\section{Introduction}

Histologically, congenital hyperinsulinism may be broadly classified into focal and diffuse forms. Although they present with similar clinical manifestations, they differ in the management required. Focal forms of $\mathrm{CHI}$, unlike the diffuse forms are amenable to surgery without any long term sequlae. ${ }^{4}$ Owing to the fact that, neartotal pancreactectomy often leads to post-operative hypoglycemias in $60 \%$ children and insulin-dependent diabetes mellitus by puberty in most, and that many diffuse forms of HI show spontaneous resolution after years of treatment, an aggressive medical treatment approach for diffuse disease is preferred to surgery. ${ }^{5,6}$ Current approach to medical management of $\mathrm{CHI}$ is aimed to achieve euglycemia through glucose infusion or increased intake of carbohydrates along with administration of medications which inhibit excess secretion of insulin like diazoxide and somatostatin analogues. ${ }^{7}$ Severe forms of diffuse HI which do not respond to diazoxide, are usually treated with octreotide which is administered subcutaneously every $6-8 \mathrm{hrs} .{ }^{8}$ Octreoctide has few transient GI side effects, with rare long term complications of gallbladder sludge/stones. However, it is generally not recommended in neonates because of possibility of fatal NEC. ${ }^{8}$ The major drawback in treatment with octreoctide is the need of multiple daily injections. Several studies have being conducted on long-acting somatostatin analogues to study their effectiveness on disease control as well as the quality of life of patients/parents owing to the once monthly dosing. . $^{2,9}$ There are two available forms of long-acting SST analogues-LAR octreoctide and octreoctideautogel. Sandostatin LAR Depot is a long-acting dosage form consisting of microspheres of the biodegradable glucose star polymer, D,L-lactic and glycolic acids copolymer, containing octreotide. It maintains all of the clinical and pharmacological characteristics of the immediaterelease dosage form octreotide with the added feature of slow release of octreotide from the site of injection, reducing the need for frequent administration. We report our experience with long acting octreotide, LAR octreoctide in the management of a 3 and half yr old Kuwaiti child diagnosed with diffuse CHI (Figure 1).

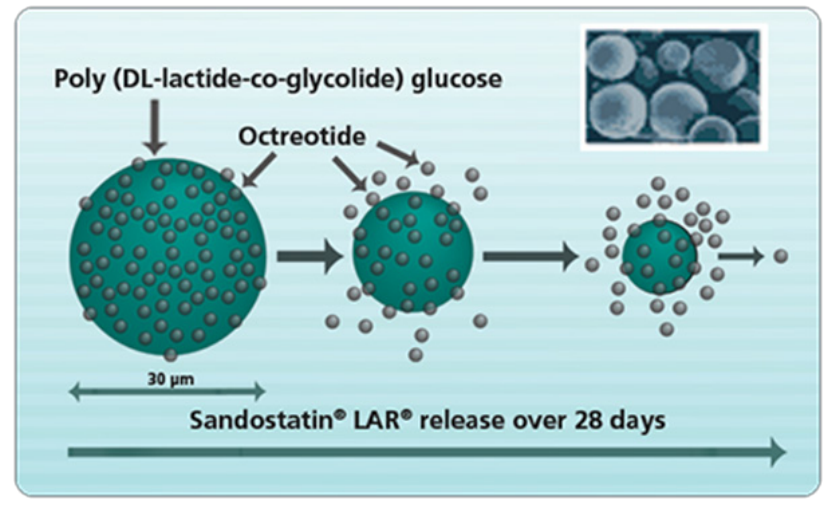

Figure 1 Shows the extended release of octreotide LAR over 28 days.

\section{Case report}

A female infant was born full term, SVD, with a birth weight of $4.3 \mathrm{~kg}$, in good general condition to consanguineous parents. She had 3 healthy siblings and there was no relevant family history. At 6 days of age, the patient was admitted to the hospital with a history of abnormal movement, poor feeding and lethargy. The baby looked chubby with no dysmorphic features and systemic review was unremarkable. Blood glucose at the time of admission was $<2.2 \mathrm{mmol} / \mathrm{L}$ which was initially corrected by bolus of $10 \%$ dextrose. During her hospital stay, she had recurrent hypoglycemic episodes. Serum insulin levels were sent twice during hypoglycemia (with blood sugar $<2.6 \mathrm{mmol} / \mathrm{L}$ ) which revealed high insulin levels of $33.5 \mathrm{UIU} / \mathrm{ml}$ and $34.5 \mathrm{UIU} / \mathrm{ml}$. Growth hormone, cortisol and free fatty acids levels were normal. IV glucagon $(30 \mathrm{mcg} / \mathrm{Kg})$ stat dose was given during hypoglycemic episode, and blood glucose level was seen to rise from $<2.6 \mathrm{mmol} / \mathrm{L}$ to $3 \mathrm{mmol} / \mathrm{L}$ after $15 \mathrm{mins}$ of administration. The baby was initially treated with IV fluids and oral feeds. Oral diazoxide was later started at a dose of $4 \mathrm{mg} / \mathrm{kg} / \mathrm{dose} 8 \mathrm{hrly}$, which was increased to $6 \mathrm{mg} / \mathrm{kg} / \mathrm{dose}$ $8 \mathrm{hrly}$. SC Octreotide was added to the treatment at a dose of $5 \mathrm{mcg} / \mathrm{kg} /$ 
dose every $6 \mathrm{hrs}$ and diazoxide was discontinued, after the blood sugar was stabilized. She was discharged home on Octreotide $4 \mathrm{mcg} / \mathrm{kg} / \mathrm{dose}$ SC every $6 \mathrm{hrs}$ along with oral feeds $150 \mathrm{ml} / 4 \mathrm{hrs}$ with 2 spoons of polycose with each meal. With this regime, her blood glucose was seen to range between $4-6 \mathrm{mmol} / \mathrm{L}$, with infrequent hypoglycemic events.

A PET/CT scan showed no abnormal focal uptake within the pancreas or abdominal region. Genetic study was done which revealed that patient is homozygous for ABCC 8 missence mutation, p. Ala390Glu, consistent with the diagnosis of autosomal recessive congenital hyperinsulinism.

At the age of $3 y r s$ months, she was started on LAR octreotide at a dose of $5 \mathrm{mg}$ IM while she continued on SC octreotide $0.03 \mathrm{mg} 6 \mathrm{hrly}$. She was screened by abdominal ultrasonograph for gallbladder stones

Table I Continous glucose monitoring data $(\mathrm{mmol} / \mathrm{L})$

\begin{tabular}{|c|c|c|c|c|c|c|c|}
\hline & $24 / 11$ & $25 / 11$ & $26 / 1 /$ & $27 / 1 /$ & $28 / 1$ I & $29 / 11$ & $30 / 1 / 1$ \\
\hline Highest & 7.4 & 8.4 & 9.2 & 10 & 8.7 & 9 & 5.2 \\
\hline Lowest & 3.4 & 3.3 & 3.7 & 3.1 & 2.9 & 3.5 & 3.4 \\
\hline Average & 5.5 & 5.4 & 6.1 & 5.6 & 1.6 & 5.5 & 4.0 \\
\hline
\end{tabular}

\section{Discussion}

The management of CHI remains a challenge, especially for the diffuse forms. Surgical management of this group of children would require near total pancreactectomy which has a high incidence of diabetes mellitus later on. ${ }^{10}$ Several medications have been used for diffuse form of CHI, the first line being diazoxide usually being limited by the side effects. ${ }^{11}$ Octreotide is used as the second line of treatment for diazoxide unresponsive forms of CHI. ${ }^{11}$ Octreotide is given 6-8 hrly SC injections. Newer long-acting somatostatin analogues allow to increase the dosing interval from 3-4 times daily, to once every 4 weeks.

Our experience in treatment with such long-acting somatostatin analogue (octreotide LAR) showed good glycemic control with normal HBA1C levels and better parent satisfaction. The full blood counts and liver functions were monitored at each monthly visit and was normal. There was no evidence of cholilithiasis. The patient continues to grow in height and weight with normal IGF1 levels.

\section{Conclusion}

Further long term follow up of several patients may be required to establish the safety and efficacy of long acting octreotide in congenital hyperinsulinism. Octreotide LAR in our experience with a $3 y r$ 4month old Kuwaiti child provided a safe and effective alternative to multiple injections with better quality of life for the family.

\section{Acknowledgments}

None.

\section{Conflicts of interest}

The author declares there is no conflict of interest. during this time. During each monthly visit, the child was kept under observation for 6-8 hrs during which RBS was checked along with blood count, HBA1C, ALAT, ASAT and alkaline phosphatase. Height and weight were measured at each visit.

After the first dose of octreotide LAR she was noted to have 2 hypoglycemic episodes reaching $1.6 \mathrm{mmol} / \mathrm{L}$. Hence, the dose of octreotide LAR was increased from $5 \mathrm{mg}$ to $10 \mathrm{mg}$ IM in the next visit and subsequently to $30 \mathrm{mg}$ IM every 4 weeks. SC octreotide was discontinued after the third monthly dose of octreotide LAR. Continous glucose monitoring was done a week later which showed normoglycemia with blood glucose levels ranging between 2.9-10.0 mmol/L (Blood glucose readings in Table 1). Currently she is on $30 \mathrm{mg}$ IM octreotide every 4 weeks, and continues to grow in height and weight and is maintaining normoglycemia, without any side effects.

\section{References}

1. Arnoux JB, de Lonlay P, Ribeiro MJ, et al. Congenital hyperinsulinism. Early Hum Dev. 2010;86(5):287-294.

2. Le Quan Sang KH, Arnoux JB, Mamoune A, et al. Successful treatment of congenital hyperinsulinism with long-acting release octreotide. Eur J Endocrinol. 2012;166(2):333-339.

3. Yorifuji T. Congenital hyperinsulinism: current status and future perspectives. Ann Pediatr Endocrinol Metab. 2014;19(2):57-68.

4. Petraitiene I. Congenital hyperinsulinism. Medicina (Kaunas). 2014;50(3):190-195

5. Glaser B, Hirsch HJ, Landau H. Persistent hyperinsulinemic hypoglycemia of infancy: long-term octreotide treatment without pancreatectomy. J Pediatr. 1993;123(4):644-650.

6. Mazor-Aronovitch K, Gillis D, Lobel D, et al. Long-term neurodevelopmental outcome in conservatively treated congenital hyperinsulinism. Eur J Endocrinol. 2007157(4):491-497.

7. Kane C, Lindley KJ, Johnson PR, et al. Therapy for persistent hyperinsulinemic hypoglycemia of infancy. Understanding the responsiveness of beta cells to diazoxide and somatostatin. J Clin Invest. 1997;100(7):1888-1893.

8. Mohamed Z, Arya VB, Hussain K. Hyperinsulinaemic hypoglycaemia: genetic mechanisms, diagnosis and management. J Clin Res Pediatr Endocrinol. 2012;4(4):169-181.

9. Modan-Moses D, Koren I, Mazor-Aronovitch K, et al. Treatment of congenital hyperinsulinism with lanreotide acetate (Somatuline Autogel). J Clin Endocrinol Metab. 2011;96(8):2312-2317.

10. Hussain K. Diagnosis and management of hyperinsulinaemic hypoglycaemia of infancy. Horm Res. 2008;69(1):2-13.

11. Arya VB, Mohammed Z, Blankenstein O, ET AL. Hyperinsulinaemic hypoglycaemia. Hormone and Metabolic Research. 2014; 46(3):157170 . 